Recebido: 04/11/2015

Aprovado: 27/01/2016

\title{
A história de gente comum: o cotidiano de uma favelada
}

\author{
Pollyana dos Santos Silva Costa
}

Resumo: O presente trabalho tem como objetivo realizar uma análise da obra Quarto de despejo, de Carolina Maria de Jesus, a partir da perspectiva da História Social. Tendo em vista que a experiência vivida pelas pessoas comuns de determinado período histórico pode ser esclarecedora da realidade social, política e econômica característica desse referido contexto, investigarei o diário da escritora como uma fonte documental da década de 1950 no Brasil.

Palavras-chave: Experiência, Cotidiano, Sociedade, Carolina Maria de Jesus, História Social.

Abstract: This article intends to analyze the work "Quarto de despejo", from Carolina Maria de Jesus, since Social History perspective. With regards to the living experience by the ordinary people in certain time of history can clarify ones social, political and economical realities within this context, I have searched the writers diaries as an documental source from the 1950's in Brazil.

Keywords: Experiences; Everyday; Society; Carolina Maria de Jesus; Social History.

\footnotetext{
* Doutoranda em Literatura e Práticas Sociais pela Universidade de Brasília. Bolsista da CAPES. E-mail: pollyanassilva@gmail.com
} 


\section{Experiência em História Social}

As pesquisas em História Social têm dado ênfase à questão da experiência dos indivíduos como elemento que permite entender o conjunto de práticas sociais de determinados sujeitos historicamente localizados. Uma vez que, nessa perspectiva, o objeto final da pesquisa histórica é o homem em sociedade (MATTOS, 1997), a análise de atividades cotidianas de determinados grupos possibilita a compreensão da maneira como os sujeitos estabelecem seus modos de viver. Para alcançar tal objetivo, a investigação em História Social se propõe a interpretar hábitos de grupos considerados marginais na história oficial a fim de compreender a história como uma construção particular de cada época.

O foco na investigação da vivência da coletividade se explica pelo fato de que é o grupo social que "propõe ou impõe aos indivíduos os seus quadros de pensamento" (SOBOUL, p. 27). Nesse sentido, Paul Ricoeur destaca que as memórias de um indivíduo se estabelecem a partir de sua experiência de pertencer a um grupo do qual aprende as práticas sociais (2007, p.130).Além disso, vale lembrar que os sujeitos são construídos discursivamente dentro das configurações da trama social a qual pertencem. Assim, cada indivíduo desempenha um papel que lhe é conferido pela coletividade.

Entretanto, é preciso tomar cuidado com os caminhos pelos quais tal pensamento nos poderia levar. Pressupor que o indivíduo seria apenas o espelho do grupo em que está inserido é uma ideia enganosa. Pois, apesar de influenciado pelas práticas do veículo social, cada sujeito, enquanto um agente social interpreta as experiências coletivas a partir de sua subjetividade, e assim, se constrói enquanto também é construído pelo grupo em que está inserido.

Nesse sentido, explica-se o fato de, mesmo em sociedades aparentemente coesas, surgirem, por vezes, indivíduos que se destacam por apresentar um comportamento diferenciado com relação aos demais integrantes do grupo do qual faz parte. No entanto, a investigação de tais sujeitos é um recurso precioso para as pesquisas em História Social, pois, ainda que apresente uma conduta diversa do restante da coletividade, a interpretação de aspectos relacionados à sua experiência torna-se elucidativa da realidade em que se encontravam, bem como, da maneira como pensam essa sociedade. Isso porque, por mais que se distancie das práticas comuns, o sujeito não consegue se desvincular totalmente do contexto em que vive. 
Diante disso, propõe-se, como objeto de estudo, a investigação de uma obra literária produzida por um desses indivíduos que parecem destacar-se em meio ao seu grupo: Carolina Maria de Jesus.

\section{O objeto}

Nascida na cidade mineira de Sacramento em 14 de março de 1914, Carolina Maria de Jesus mudou-se para São Paulo em 1937, após a morte da mãe. Na metrópole, trabalhou primeiramente como empregada doméstica e depois como catadora de papel para sustentar seus três filhos. Morava em um barraco que ela mesma construiu com papelão, madeirite, latão e outros materiais, na extinta favela do Canindé. No ano de 1958, o repórter Audálio Dantas preparava uma reportagem sobre um parque infantil no local, quando se deparou com essa mulher negra de 43 anos que gritava: “Onde já se viu uma coisa dessas, uns homens grandes tomando brinquedo de criança! Deixe estar que eu vou botar vocês todos no meu livro!" Logo, o jornalista descobriu que a mulher tinha escritos em seu barraco "uns vinte cadernos encardidos.” Tratava-se do diário de Carolina Maria de Jesus.

$\mathrm{O}$ jornalista percebeu nesses registros um material em potencial para a reportagem que pretendia produzir sobre a comunidade que se espalhava às margens do Tietê. Uma vez que tal relato trazia a visão de dentro da favela que somente um morador poderia ter.De fato, a matéria foi publicada no jornal A Folha da Noite em 1958 e alcançou grande repercussão entre o público leitor. No ano de 1959, já trabalhando no diário O Cruzeiro, Audálio Dantas realizou uma nova matéria com Carolina Maria de Jesus, divulgando ali também alguns trechos de seu diário.

No ano posterior, o livro foi finalmente publicado. No entanto, é interessante investigar a maneira como se deu a escolha e a edição do material para a montagem do livro. Segundo Audálio Dantas, "a repetição da rotina da favelada, por mais fiel que fosse, seria exaustiva", tendo em vista que se tratava de 20 cadernos. Portanto, era necessário fazer alguns cortes. O jornalista delimitou, então, como corpus, os relatos escritos no período de 15 de julho de 1955 a $1^{\circ}$ de janeiro de 1960, sendo que o diário de 1955 encerra-se no dia 28 de julho, depois há um salto para maio de 1958 e o ano de 1959 é descrevidoaté o mês de agosto. Além disso, vários dias deixam de ser registrados na edição do livro. Dessa forma, a maior parte do relato se concentra no ano de 1958. 
Afora o recorte de tempo, o editor afirma ter diminuído a quantidade de vezes que a palavra fome e seus termos correlatos aparecem no texto sem, contudo, "diminuir a sua importância na tragédia da favelada". Admite, ainda, ter feito algumas correções de pontuação e grafia a fim de melhorar a compreensão dos leitores.

No entanto, é importante investigar os motivos que levaram Audálio Dantas a escolher esses trechos do diário de Carolina, em detrimento de outros. A esse respeito, o prefácio que o jornalista faz no livro nos deixa algumas pistas. De acordo com ele, sua participação na obra relaciona-se com sua própria experiência uma vez que, afirma ter entrado nessa história “como jornalista, verde ainda, com a emoção e a certeza de quem acredita poder mudar o mundo. Ou, pelo menos, a favela do Canindé e outras favelas espalhadas pelo Brasil.” Essa fala do jornalista pode ser um indício de sua escolha política, bem como de sua maneira de pensar à época da edição do livro. É possível também que explique a escolha dele pela publicação de trechos que relatam de maneira mais intensa as diferenças sociais existentes no Brasil do fim da década de 1950 e os sofrimentos vividos pela população de favelados, conforme pode-se observar no trecho abaixo:

10 de maio de 1958 - Fui na delegacia e falei com o tenente. Que homem amável! Se eu soubesse que ele era tão amável, eu teria ido na delegacia na primeira intimação (...) O tenente interessou-se pela educação dos meus filhos. Disse-me que a favela é um ambiente propenso, que as pessoas tem mais possibilidades de delinquir do que tornar-se útil a pátria e ao país. Pensei: Se ele sabe disso, porque não faz um relatório e envia para os políticos? O senhor Janio Quadros, o Kubstchek e o Dr. Adhemar de Barros? Agora falar para mim, que soiu uma pobre lixeira. Não posso nem resolver as minhas dificuldades.

O Brasil precisa ser dirigido por uma pessoa que já passou fome. A fome é professora. Quem passa fome aprende a pensar no próximo, e nas crianças (JESUS, 2013, p. 29).

O relato acima traz uma severa crítica social de Carolina às injustiças sociais perpetuadas no Brasil, e, ao selecionar esse fragmento para constar do livro, o editor, de certa forma, reforça e legitima essa crítica. Note-se que o trecho acima se situa em determinado contexto sociopolítico brasileiro. À época, o país tinha como presidente Juscelino Kubstchek, cuja meta era alcançar "50 anos de progresso em 5 anos de governo" e, para isso, previa um acelerado crescimento econômico a partir da expansão da indústria. Apesar de ter alcançado notável desenvolvimento pelo processo de aceleração industrial, o país contava com uma realidade de grande desigualdade social que parecia ser encoberta pela propaganda de cunho ideológico empreendido pelo governo. Segundo Moreira (2003), foi essa campanha a 
responsável por convencer proletários, camponeses e classe média a sustentar um modelo que, na realidade, visava a consolidação da burguesia industrial. Assim, era oferecido um desenvolvimento nacional como algo para todos (p. 165).

Constata-se, portanto, que nenhuma investigação é totalmente neutra, ela sempre será contaminada pela visão de mundo do pesquisador em maior ou menor escala, nesse sentido, a pesquisa em História ou em qualquer outra área do conhecimento humano seria uma representação. Porém é preciso atentar para uma questão apontada por Thompson (1981) no que diz respeito à experiência. Segundo o autor, não se pode negar que as experiências dos sujeitos existiram de fato e, sendo assim, o real também existe, ou seja, nem tudo se trata de representação. Nesse sentido, ainda que os escritos da favelada tenham sido selecionados por uma pessoa com concepções políticas próprias, não se pode negar que Carolina Maria de Jesus existiu, morou na Favela do Canindé e escreveu um diário, onde relatou, dentre outras coisas, os sofrimentos de seu cotidiano. É precisamente o relato da experiência cotidiana das pessoas comuns, o objeto de estudo da História Social.

\section{O cotidiano de uma favela em São Paulo na década de 1950}

O título dado ao diário de Carolina Maria de Jesus nasceu de uma metáfora utilizada pela autora para definir a favela "eu denomino que a favela é o quarto de despejo de uma cidade. Nós, os pobres, somos os trastes velhos." De fato, o surgimento da favela do Canindé em São Paulo se deu devido à desocupação das casas térreas dos cortiços situados em bairros tradicionais para a construção de prédios, no final da década de 1940. Esse foi um fenômeno que mudou a configuração de moradia da cidade de São Paulo, uma vez que a construção dos arranha-céus e dos condomínios aliava-se à ideia de progresso e desenvolvimento. Do outro lado, os despejos cresciam e iam se tornando um tormento para que morava de aluguel. Segundo Silva:

Nesse período crítico, as ações de despejo representavam, no mínimo, 45 mil pessoas que ficaram desalojadas, numa conjuntura de absoluta carência de moradias na cidade. Os despejados não tinham qualquer chance de obter uma moradia por um preço sequer próximo ao que pagavam. Sem encontrar alternativa de moradia de aluguel compatível com seus rendimentos em local próximo ao emprego, muitas famílias despejadas ou recém-chegadas do campo ocuparam terrenos baldios, sobretudo nas várzeas dos rios Tamanduateí e Tietê [...] Nas décadas de 1940 e 1950 surgiram favelas como 
a da Baixada do Penteado, Ibirapuera, Canindé, Ordem e Progresso, da Lapa... (2010, p.69).

A escritora de Quarto de Despejo demonstra ter consciência dessa violência cometida contra os mais pobres em nome do progresso e utiliza-se de sua escrita para denunciá-la. Apesar de seu cotidiano ser marcado por uma rotina de atividades como buscar água, catar lixo, trocar o papel por dinheiro, comprar comida, entre outras coisas, Carolina Maria de Jesus enxerga o fato de estar sendo oprimida por um sistema de poder e relata isso em suas memórias (LUDTKE, 1995, p.5).

Por isso, muito presente na escrita de Carolina está o tema da fome, bem como a dificuldade diária em conseguir alimentar a si e a seus filhos, conforme observa-se nos seguintes trechos:

E ainda:

18 de julho - Levantei as 7 horas. Alegre e contente. Depois que veio os aborrecimentos. Fui ao depósito receber... 60 cruzeiros. Passei no Arnaldo. Comprei pão, leite, paguei o que devia e reservei dinheiro para comprar Licor de Cacau para Vera Eunice.

[...]

19 de julho - Despertei 7 horas com a conversa dos meus filhos. Deixei o leito, fui buscar água [...] Fui no depósito receber o dinheiro do papel, 55 cruzeiros. Retornei depressa, comprei leite e pão. Preparei Toddy para as crianças, arrumei os leitos, puis feijão no fogo, varri o barraco (JESUS, 2013, pp. 15/17).

27 de maio - Percebi que no Frigorífico jogam creolina no lixo, para o favelado não catar a carne pra comer. Não tomei café, ia andando meio tonta. A tontura da fome é pior do que a do álcool. A tontura do álcool nos impede de cantar. Mas a da fome nos faz tremer. Percebi que é horrível ter só ar dentro do estomago. Comecei a sentir a boca amarga. Pensei: já não basta as amarguras da vida? (p.44).

Esses fragmentos são reveladores não somente da situação vivida pela protagonista da obra, mas de todo um contexto social brasileiro da década de 1950, especialmente no que se refere ao cotidiano de pessoas que viviam em favelas. No entanto, deve-se salientar que, embora o texto de Carolina seja utilizado como a representação da escrita favelada, a autora não se identificava como tal. Em diversos trechos da obra, ela afirma não ser semelhante aos vizinhos e, pelo fato de ser alfabetizada e escrever um diário, também é percebida como diferente por eles, conforme se observa no seguinte fragmento: 
18 de julho - Levantei as 7 horas. Alegre e contente. Depois que veio o aborrecimento [...] A dona Rosa, assim que viu meu filho José Carlos começou impricar com ele. Não queria que o menino passasse perto do barracão dela. Saiu com um pau para espancá-lo [...] Surgio a dona Cecília. Veio repreender meus filhos. Lhe joguei uma indireta e ela retirou-se [...] Veio a indolente Maria dos Anjos. Eu disse: - Eu estava discutindo com a nota, já começou chegar os trocos. Os centavos [...] Veio a dona Sílvia reclamar contra os meus filhos (pp. 15-16).

Ciente da situação de miséria em que vive, mas determinada a sair da favela, Carolina Maria de Jesus declara ainda que lá não é seu lugar e que nem considera o barraco como casa, "Cheguei na favela: eu não acho jeito de dizer que cheguei em casa. Casa é casa. Barracão é barracão" (p.47).

Diferentemente do conceito que a favela adquiriu ao longo dos anos e que chegou aos dias atuais como sinônimo de comunidade, deixando implícita a ideia de relação afetiva entre vizinhos, o surgimento desse tipo de moradia remete a situações de opressão que marcaram a história.

Sabe-se que, com o fim do regime escravocrata no século XIX, o contingente populacional da zona urbana cresceu de forma absurda. Nas cidades, os negros não conseguiam emprego e permaneciam marcados por estigmas sendo, agora, considerados vagabundos errantes. No entanto, à medida que conflitos iam surgindo no território nacional, esses andarilhos eram recrutados pelo exército para combater os revoltosos. Dentre essas guerras, destaca-se a de Canudos que culminou com a morte de cerca de 25 mil pessoas e o retorno dos soldados do campo de batalha. Como não recebiam o salário referente à sua atuação na batalha, os soldados decidiram deslocar-se para o Rio de Janeiro e pressionar o Ministério da Guerra, porém, não obtiveram sucesso. Instalaram-se, então, no Morro da Providência, posteriormente batizado como Morro da Favela (em referência a uma planta comum em Canudos que também dava nome a um morro do local). Posteriormente, outras pessoas, muitas vezes oriundas de outros estados, foram se juntando aos primeiros moradores do local.

É esse passado de dominação e opressão sofrida pela população negra no Brasil que está por trás da constituição das favelas. Esse era o lugar dos indesejados pela burguesia, onde deveriam permanecer esquecidos e invisíveis aos demais integrantes da sociedade.

Nesse contexto, Carolina Maria de Jesus se enquadra e, novamente, enquanto sujeito de sua história, percebe a segregação que lhe é imposta quando declara que: 
Os vizinho de alvenaria olha os favelados com repugnância. Percebo seus olhares de ódio porque não quer a favela aqui. Que a favela deturpou o bairro. Que tem nojo de pobreza. Esquecem eles que na morte todos ficam pobres.

O que eu sei é que praga de favelados pega. Quando nós mudamos para a favela, nós íamos pedir água nos vizinhos de alvenaria. Quem nos dava água era a dona Ida Cardoso. Treis vezes ela nos deu água. Ela nos disse que nos dava água só nos das uteis. Aos domingos ela queria dormir até mais tarde. Mas o favelado não é burro. Um dia foram buscar água e não encontraram a torneira no jardim, onde os favelados pegava água (p. 55).

A escritora compreende, ainda, a situação deplorável em que o local fora construído "eu tenho muito nojo daqui. Isto aqui é lugar para os porcos. Mas se pusessem os porcos aqui, haviam de protestar e fazer greve" (p. 48).A partir desse relato, observa-se que a protagonista não se identificava como participante da comunidade em que vivia, mas como uma vítima da pobreza que fora obrigada a mudar para a favela do Canindé. Assim, enquanto ser que age e que constrói sua própria história (dentro das possibilidades que lhe são dadas), Carolina Maria de Jesus não se conforma com a realidade social que lhe é imposta, usando a escrita como instrumento de denúncia, mas também de libertação da opressão em que vive. No entanto, ao fazer isso, ela não relata apenas sua experiência em seu diário, mas acaba narrando a experiência de toda a coletividade, pois compartilha essa realidade com o grupo do qual faz parte.

\section{Considerações finais}

A investigação de vivências de pessoas comuns tem sido o instrumento de estudo da História Social. Isso porque esse campo de trabalho prioriza a experiência humana, bem como os processos que diferenciam e individualizam os comportamentos do sujeito (MATTOS, 1997). Deve-se ater, no entanto, para o fato de que, apesar de cada pessoa possuir sua maneira peculiar de pensar o mundo e comportar-se nele, suas possibilidades são limitadas à realidade em que vive, ou seja, aquilo que lhe é imposto socialmente. Sendo assim, compreende-se que os sujeitos são agentes cuja atuação em sociedade é constituída por meio do status que lhe é atribuído. Nesse sentido, a investigação do diário de Carolina Maria de Jesus torna-se relevante na pesquisa em História Social.

Entretanto, dentro de uma realidade social, as mudanças de comportamentos e concepções são possíveis graças à atuação desses indivíduos que agem de maneira diferenciada da maioria de seus pares, posto que o processo em que estão inseridos é 
dinâmico (BARTH, 1981). Ao compreender-se como ser oprimido pela desigualdade social em que vivia e denunciar essa realidade, a autora de Quarto de Despejo constitui-se como uma dessas "pessoas extraordinárias" que exemplificam a maneira de pensar de seu tempo.

\section{Referências bibliográficas}

\section{Fonte primária}

JESUS, Maria Carolina. Quarto de despejo: diário e uma favelada. São Paulo: Abril educação, 2013.

\section{Fontes secundárias}

BARTH, F. Processandform in social life. London: Routledge e Kagan Paul, 1981.

LUDTKE, Alf. What is the history of everyday life and Who are its practitiones? In, LUDTKE,A.(ed.)The history of everyday life . Reconstructing historical experiences and waysoflife. Princeton: Princeton University Press, 1995.

MATTOS, H. "História Social.” In, CARDOSO, S. e VAIFAS, R. (ed.) Domínios da História: ensaios de teoria e de metodologia. Rio de Janeiro: Editora Campus, 1997.

MOREIRA, V. "Os anos JK: industrialização e modelo oligárquico de desenvolvimento" In. FERREIRA, J. (org.) O Brasil republicano. O tempo da experiência democrática: da democratização de 1945 ao golpe civilmilitar de 1964. Rio de Janeiro: Civilização brasileira, 2003.

RICOEUR, P. A memória, a história e o esquecimento. Campinas: Ed. Unicamp, 2007.

SILVA, M. V. Representações da cidade de São Paulo na música popular. São Paulo: Biblioteca 24 horas, 2010.

SOBOUL, A. "Descrição e medida social em História Social." In, GODINHO, V.M. (dir.) A História Social: problemas, fontes e métodos. Lisboa: Edições Cosmos, 1973.

THOMPSON, E. A miséria da teoria ou um planetário de erros. Uma crítica ao pensamento de Althusser. Rio de Janeiro: Zahar, 1981. 